\title{
Microbiological synthesis of methyl ethyl ketone
}

\author{
Anna Astashkina ${ }^{1, *}$, Yuliya Kolbysheva ${ }^{1}$, Alena Nikiforova ${ }^{1}$, and Abdigali Bakibayev ${ }^{2}$ \\ ${ }^{1}$ Tomsk Polytechnic University, Institute of natural resources, Tomsk, Russia \\ ${ }^{2}$ Tomsk State University, 634050 Tomsk, Russia
}

\begin{abstract}
Optimal conditions for the microbiological synthesis of methyl ethyl ketone (MEK) on the mineral medium with butanol-1, butanol-2, 2methylpropanol-2 by hydrocarbon-oxidizing bacteria Pseudomonas spp. were chosen. Optimal conditions for microbiological synthesis are liquid mineral Adkins' medium containing 3\% (vol.) of the substrate, stirring speed $-80-100 \mathrm{rev} / \mathrm{min}$, temperature $-37^{\circ} \mathrm{C}$, and synthesis time $24-48$ hours. The specific growth rate and time of culture generation during the microbial synthesis were determined. It was found that methyl ethyl ketone is formed in the reaction mixture after 8,48 and 72 hours when using 2methylpropanol-2, butanol-2, butanol-1 as substrates, respectively. Maximum methyl ethyl ketone yield in the reaction mixture is observed after 12 hours in the case of using 2-methylpropanol-2 as a carbon source and accounts for $10 \%$.
\end{abstract}

\section{Introduction}

Currently, there is interest in biotechnology worldwide. This leads to the development of methods enabling to synthesize valuable organic compounds [1-2]. Methyl ethyl ketone is a valuable selective solvent at the dewaxing units in the petrochemical industry, in the woodworking industries to produce a variety of adhesives, and other industries as well [35]. Its world production is 1.2 million tons, and the demand for it is constantly increasing on average by $7 \%$ per year. Currently, Japan, Western Europe, China, and the USA are major producers of methyl ethyl ketone. More than 10 chemical methods of producing MEK based on the catalytic oxidation of butene, dehydrogenation or oxidation of butanol, sec-butylbenzene or n-butane are known [6-20]. In industry MEK is produced by a liquid phase free radical oxidation of n-butane with the target product yield not more than $23 \%$. It should be noted that the main disadvantages of the chemical synthesis process of MEK consists in the high energy consumption, the presence of by-products, greatly complicating and increasing the cost of MEK selection process. Besides it is a long and laborious process $[12,16-20]$. Therefore, the development of environmentally safe and cost-effective process for the synthesis of methyl ethyl ketone with the use of microorganisms is important. Thus, the goal of the work consisted in the choice of optimal conditions for microbial synthesis of methyl ethyl ketone from butyl alcohols.

\footnotetext{
*Corresponding author: apa2004@mail.ru
} 


\section{Experimental}

In the work the hydrocarbon-oxidizing microorganisms of the genus Pseudomonas spp., isolated from soil and water reservoirs of Zapadno-Katylginskoe field in Strezhevoy (Tomsk region) by the company "Ecoil" (Tomsk) during the remediation of oilcontaminated land and oil, were examined. The taxonomy of pure isolated cultures was determined on the basis of the sequence analysis of nucleotides in $16 \mathrm{~S}$ pRNA, their modification and primary bioinformatical analysis (laboratory "Genotech" Ltd., Moscow). To study the bacteria viability, the bacterium culture in the amount of $5 \%$ with the concentration of CFU 108 was inoculated into liquid mineral Adkins' medium with the addition of butyl alcohols: butanol-1 (puriss p.a., GOST 6006-78), butanol-2 (puriss p.a., cas № 78-92-2), 2-methyl-2-propanol (puriss p.a., cas № 75-65-0) in the amount of 1-3\% (vol.). The cultivation was carried out at the speed of $80-1000 \mathrm{rev} / \mathrm{min}$ and temperature of $28-30^{\circ} \mathrm{C}$ within 48 hours. The number and growth dynamics of hydrocarbon-oxidizing microorganisms during the biotransformation were determined by the McCready [2] and Koch's [2] methods, using the culture media of the meat-and-peptone broth (MPB) and meat-and-peptone agar (MPA) as well. Microbiological synthesis of methyl ethyl ketone was carried out in Erlenmeyer flasks on mineral Adkins' medium with the addition of butyl alcohols as a substrate in the amount of $1 \%$ (vol.), inoculum with the concentration of CFU 108 in the amount of 5\% (vol.) within 72 hours at the temperature of $28-30^{\circ} \mathrm{C}$ and constant stirring $80 \mathrm{rev} / \mathrm{min}$. The research of residual hydrocarbons during the biotransformation of butyl alcohols was carried out by gas chromatography. For chromatographic analysis GOST R 52714-2007 was used [21]. Changes in the hydrocarbon composition of reaction mixture was measured by gas chromatography "Chromatec-Crystal 5000" with a flame ionization detector (FID) under the following conditions: column length $-100 \mathrm{~m}$, column diameter $-0.25 \mathrm{~mm}$, evaporator temperature $2900 \mathrm{C}$, oven temperature - from 0.2 to $2900 \mathrm{C}$, carrier gas - helium, carrier gas flow rate $-315 \mathrm{ml} / \mathrm{min}$; injected sample volume $-0.2 \mu \mathrm{l}$; split ratio $-200: 1$, total analysis time -20 min.

\section{Results and discussion}

Hydrocarbon-oxidizing bacteria of the genus Pseudomonas spp. are of the greatest interest [22-25]. A variety of biosynthetic and catabolic reactions, high growth rate on the simple composition media, opportunities for genetically engineered manipulation can be considered as a promising object for works in the field of biotechnology [23, 26].

Schematically the process of hydrocarbons biotransformation by bacteria $[2,25]$ can be represented as follows:

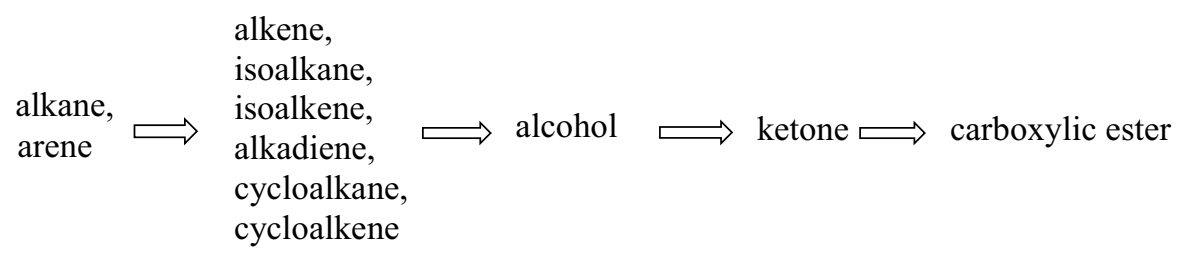

According to this scheme, simple hydrocarbons under the influence of the enzymic complex are converted to alcohols, aldehydes, ketones and etc. Therefore, it was important to examine the viability of bacteria on the mineral medium using only alcohols as a carbon source. According to published data [22-23], representatives of the genus Pseudomonas are able to assimilate ethanol as the only source of carbon nutrition in the conditions of 
submerged cultivation. At the same time they accumulate biomass, which is rich in amino acids and vitamins. Some strains such as P. aeruginosa, P. fluorescens, P. putida, P. aurantiasa, P. mendocina, and P. rathonis grow well on the synthetic medium with $1 \%$ ethanol as the only carbon source. However, only 41 strains grow well on the same medium with $2.5 \%$ ethanol. As the goal of the work was to obtain methyl ethyl ketone, so butanol-1, butanol-2, 2-methylpropanol-2 were selected as the substrate. The number of colony forming units (CFU) of bacteria on the nutrient medium with butyl alcohols was determined by limiting dilution analysis after every 8 hours. On the basis of the results of microbiological analysis, the kinetic growth curves of bacteria were made according to the amount of substrate (1-3\% (vol.)) in the reaction mixture (fig. 1-3).

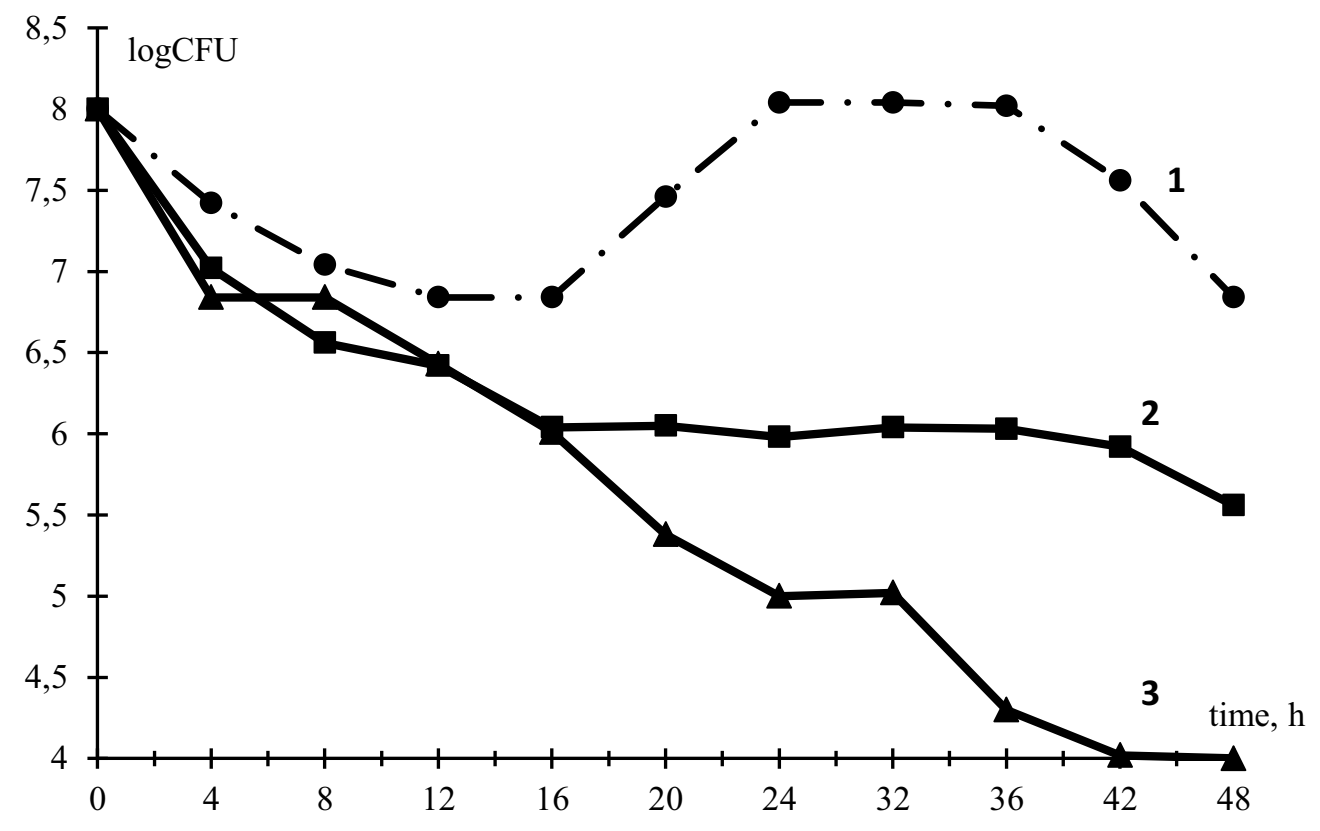

Figure 1. Changes in the number of bacteria of the genus Pseudomonas spp. on the nutrient medium with butanol-1 of different concentration, \%(vol.): 1-1, 2-2, 3-3. 


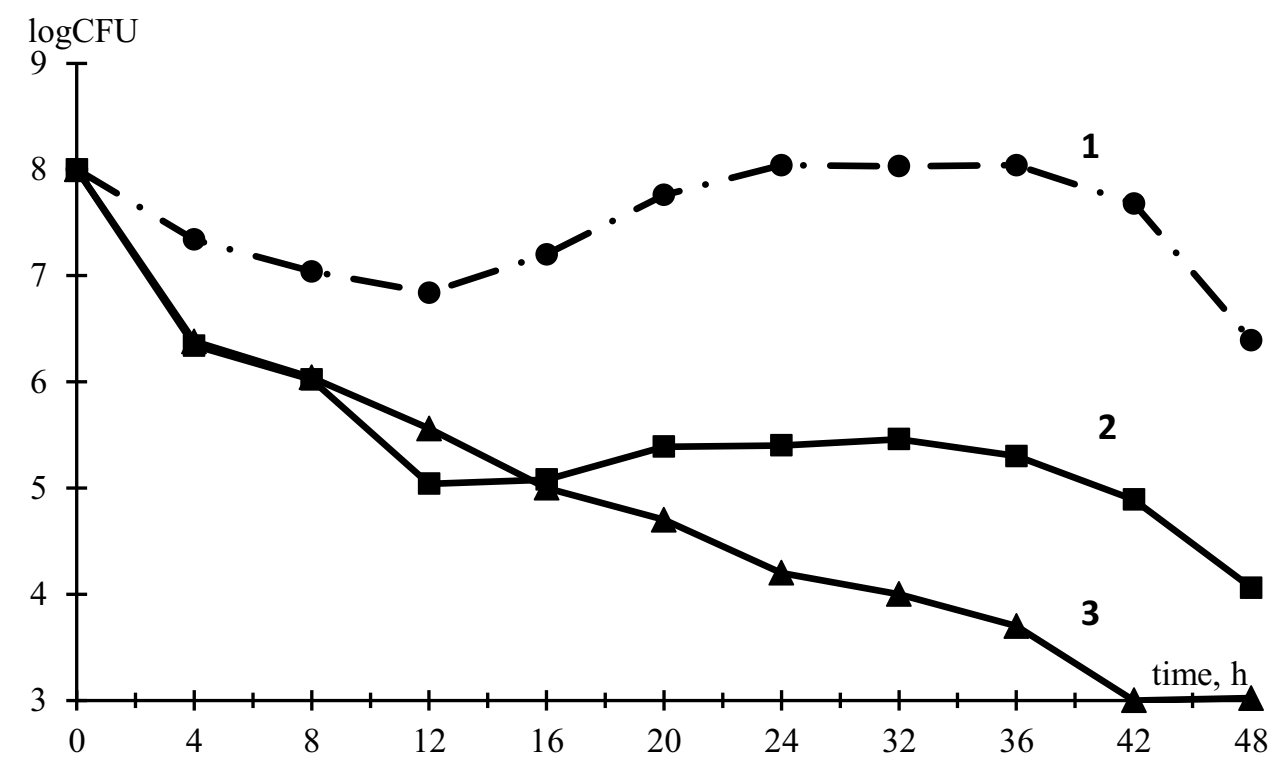

Figure 2. Changes in the number of bacteria of the genus Pseudomonas spp. on the nutrient medium with butanol-2 of different concentration, \% (vol.): 1- 1, 2-2, 3-3.

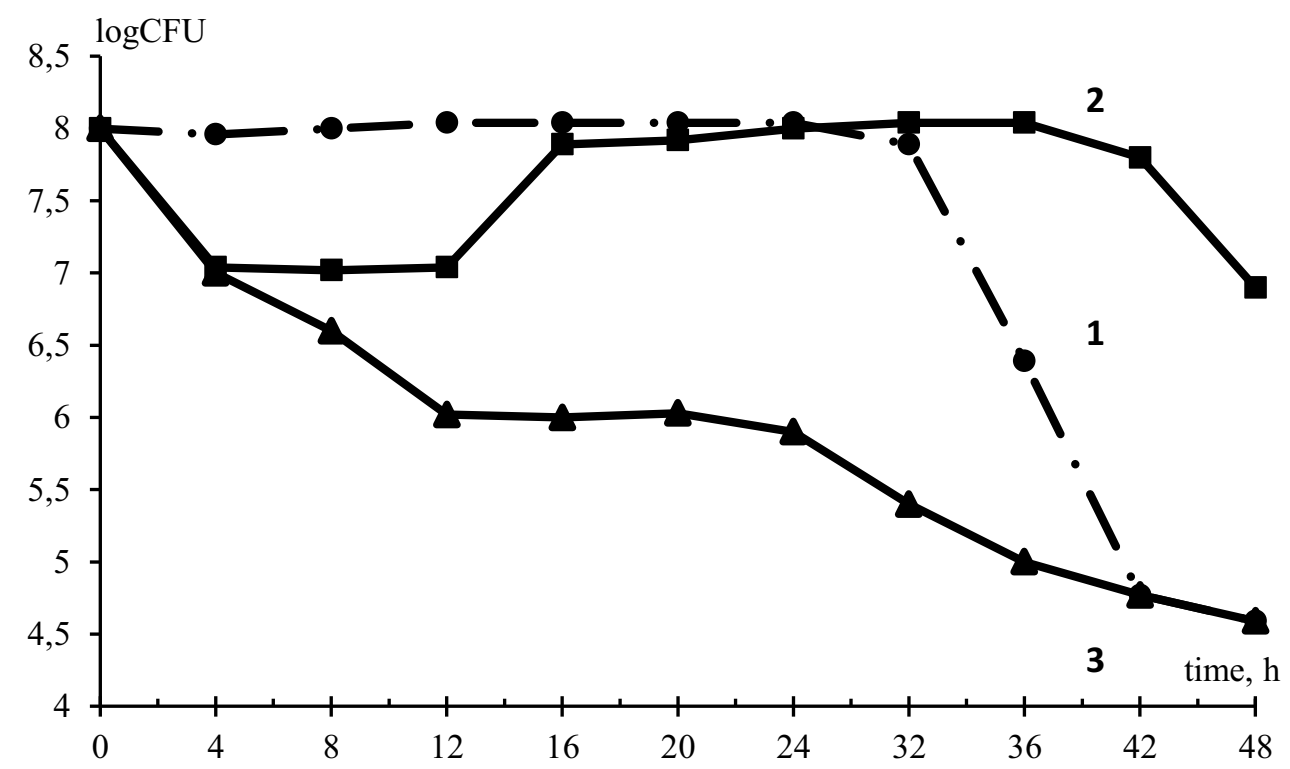

Figure 3. Changes in the number of bacteria of the genus Pseudomonas ssp. on the nutrients medium with 2-methylpropanol-2 of different concentration, \%(vol.): 1- 1, 2-2, 3-3.

According to the obtained dependences, it can be concluded that the nature and amount of substrate influence the development of a culture. Butyl alcohols added into the medium in 
the amount of more than $1 \%$ (vol.) leads to its death. The growth curves of a culture (curves 2,3 ) have complex character, which is similar to a typical growth curve with specific growth phases: induction, exponential, stationary, and death [2, 25-26]. According to figures 1-2 (curve 1), the phase of physiological adaptation of a culture to the medium continues 8-12 hours. Further, within the next 12 hours (12-24 hours), there is a maximum growth of a culture (exponential growth phase). The period after 24 hours corresponds to the stationary phase, in which the availability of essential nutrients substances becomes limited. The balance between the cell growth and division, as well as the process of cell death, is established. After 48 hours the phase of death begins as a result of the accumulation of toxic aromatic metabolites. It should be noted that in the case of 2methylpropanol-2 (1\% (vol.)) the induction and stationary phases are almost absent on the growth curve (curve 1). It shows that the studied culture was adapted to the given carbon source. However, the phase of death starts after 36 hours of cultivation due to the accumulation of toxic metabolites in all cases. On the basis of obtained data, the specific growth rate and generation time for a culture on the nutrients medium with butanol-1, butanol-2, 2-methylpropanol-2 were calculated according to the formula $[2,26]$. The results are presented in table 1 .

Table 1. Specific growth rate and generation time for bacteria of the genus Pseudomonas spp.

on the nutrients medium with butyl alcohols

\begin{tabular}{|c|c|c|c|c|c|c|}
\hline $\begin{array}{c}\text { Substrate amount, } \\
\% \text { (vol.) }\end{array}$ & \multicolumn{2}{|c|}{ Butanol-1 } & \multicolumn{2}{c|}{ Butanol-2 } & \multicolumn{2}{c|}{ 2-methylpropanol-2 } \\
\cline { 2 - 7 } & $\mathrm{K}, \mathrm{h}-1$ & $\mathrm{~g}, \mathrm{~h}$ & $\mathrm{~K}, \mathrm{~h}-1$ & $\mathrm{~g}, \mathrm{~h}$ & $\mathrm{~K}, \mathrm{~h}-1$ & $\mathrm{~g}, \mathrm{~h}$ \\
\hline 1 & 0,15 & 4,40 & 0,16 & 4,20 & - & - \\
\hline 2 & 0,01 & 1,40 & 0,05 & 3,20 & 0,10 & 4,20 \\
\hline
\end{tabular}

According to data obtained, it can be said that the structure of isomer affects the specific growth rate and generation time of hydrocarbon bacteria by the following scheme:

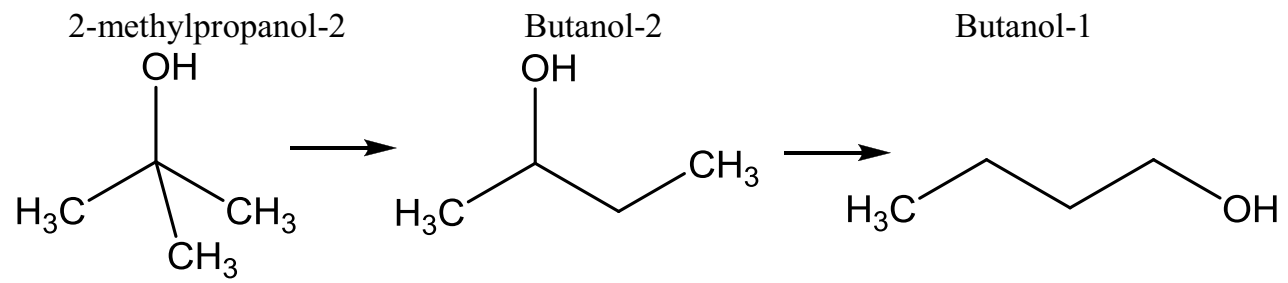

Butyl alcohol 2-methylpropanol-2 is subjected to the quicker biotransformation, because tertiary alcohols have less stable $\mathrm{C}-\mathrm{C}$ bonds than primary and secondary ones. Consequently, the chain breaking occurs easier. Furthermore, the results of microbiological analysis showed that the bacteria Pseudomonas spr. are able to assimilate butyl alcohols and can be used as a power source and energy. Microbiological synthesis time should continue at least 48 hours.

For qualitative determination of methyl ethyl ketone in the reaction mixture, the gas chromatography method was used [27]. The results of the chromatographic investigations are presented in the form of chromatograms (figure 4-6). 


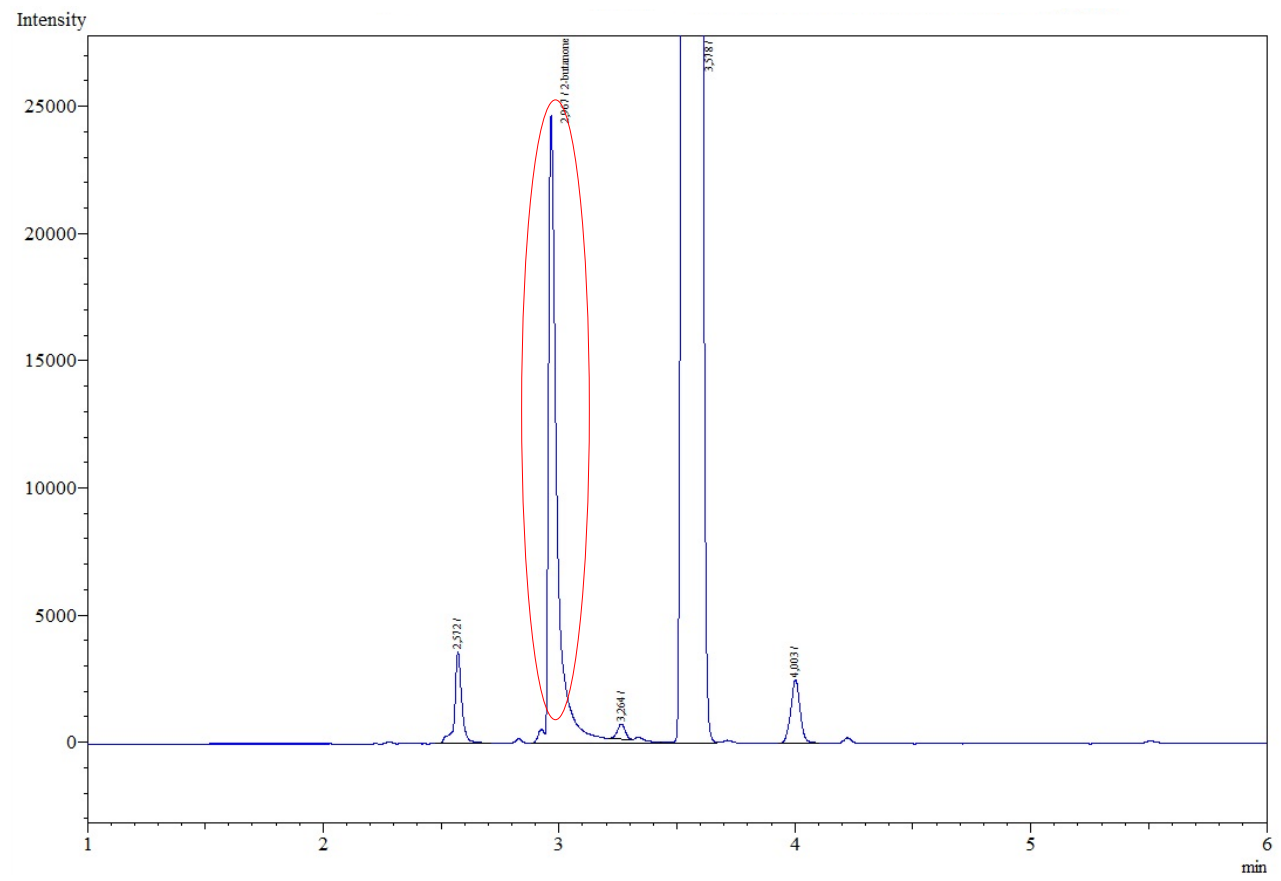

Figure 4. Chromatogram of MEK during the biotransformation of 2-methylpropanol-2 after 12 hours.

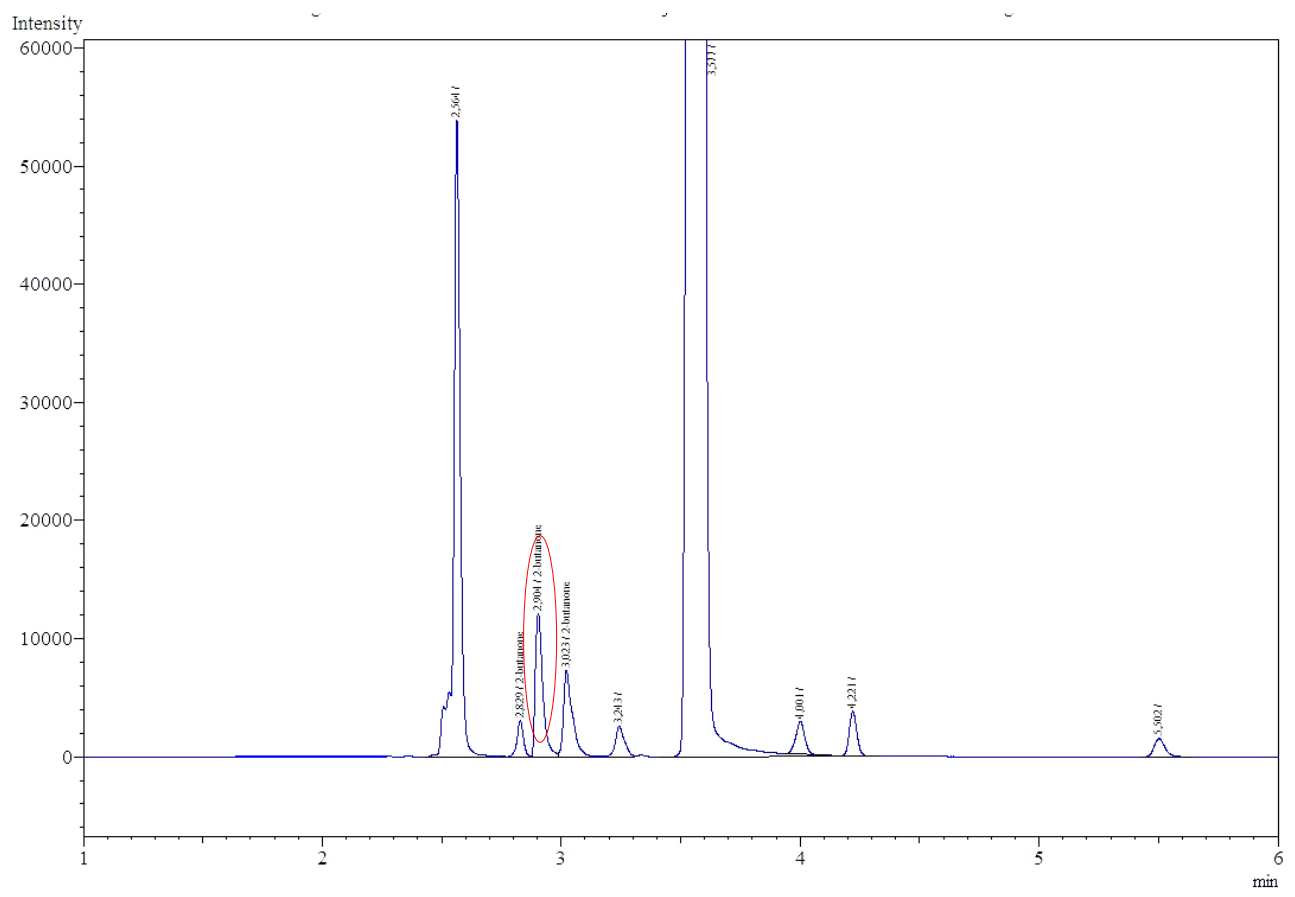

Figure 5. Chromatogram of MEK during the biotransformation of butane- 2 after 48 hours. 


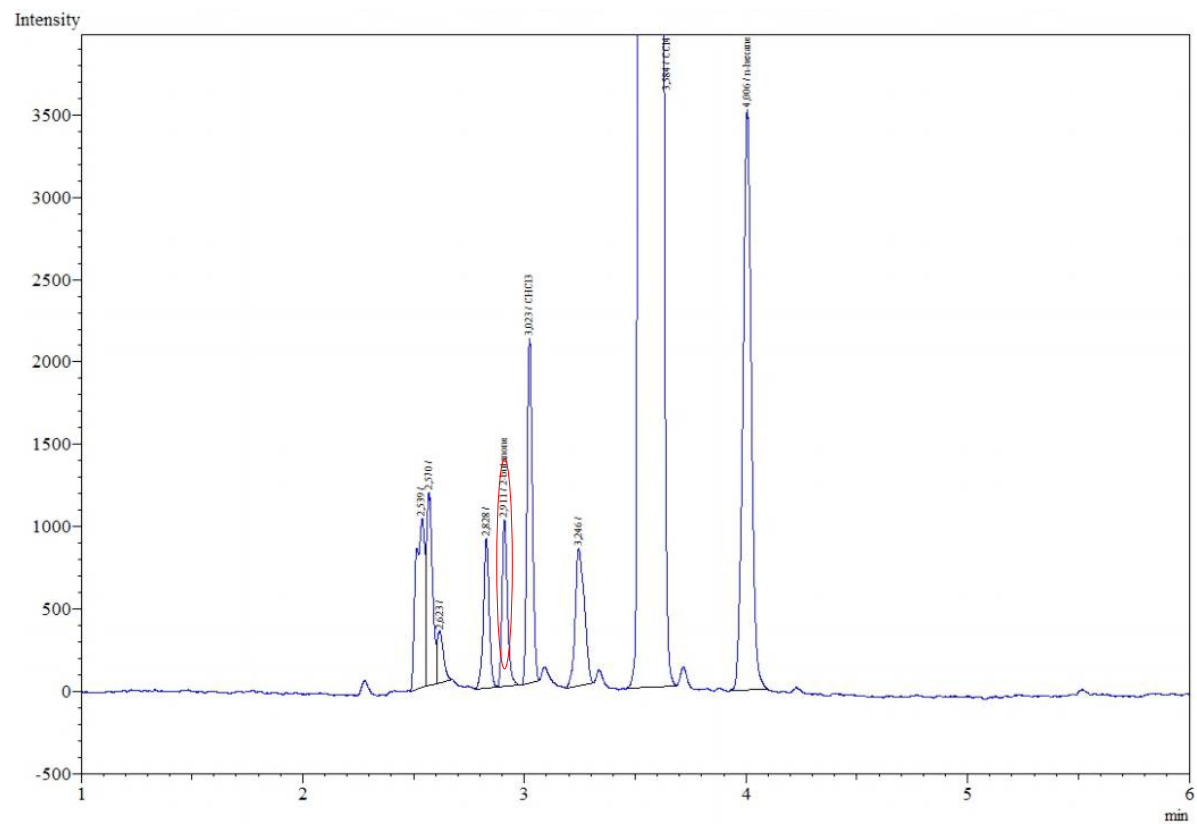

Figure 6. Chromatogram of MEK during the biotransformation butanol-1 after 72 hours.

It was determined that methyl ethyl ketone with a retention time of 3.025 was found during the cultivation of hydrocarbon bacteria of the genus Pseudomonas spp. on the nutrients medium with butyl alcohols.

Thus, the microbiological synthesis of MEK was carried out under the following conditions: mineral Adkins' medium containing 1\% (vol.) of butyl alcohols, biosynthesis time $-72 \mathrm{~h}$, temperature $-28-30^{\circ} \mathrm{C}$, stirring speed $-80 \mathrm{rev} / \mathrm{min}$. Every day sampling from the reaction mixture for the GC analysis was carried out to identify MEK. To determine MEK assay in the reaction mixture, the calibration graph was made in the axes of the peak area and MEK concentration on model solutions. To prepare model solutions, MEK in the amount of $0.1-15 \%$ (vol.) was added to the mineral Adkins' medium, extracted with carbon tetrachloride, and gas chromatographic analysis in accordance with GOST R 52714-2007 [21] was carried out within 15 minutes. Calibration graph with correlation coefficient $\mathrm{R}^{2}=$ 0.9931 was made, and the amount of MEK in the reaction mixture was calculated according to the equation $y=6247729 x$. The results of the microbiological synthesis of MEK are shown in the diagram (figure 7). 


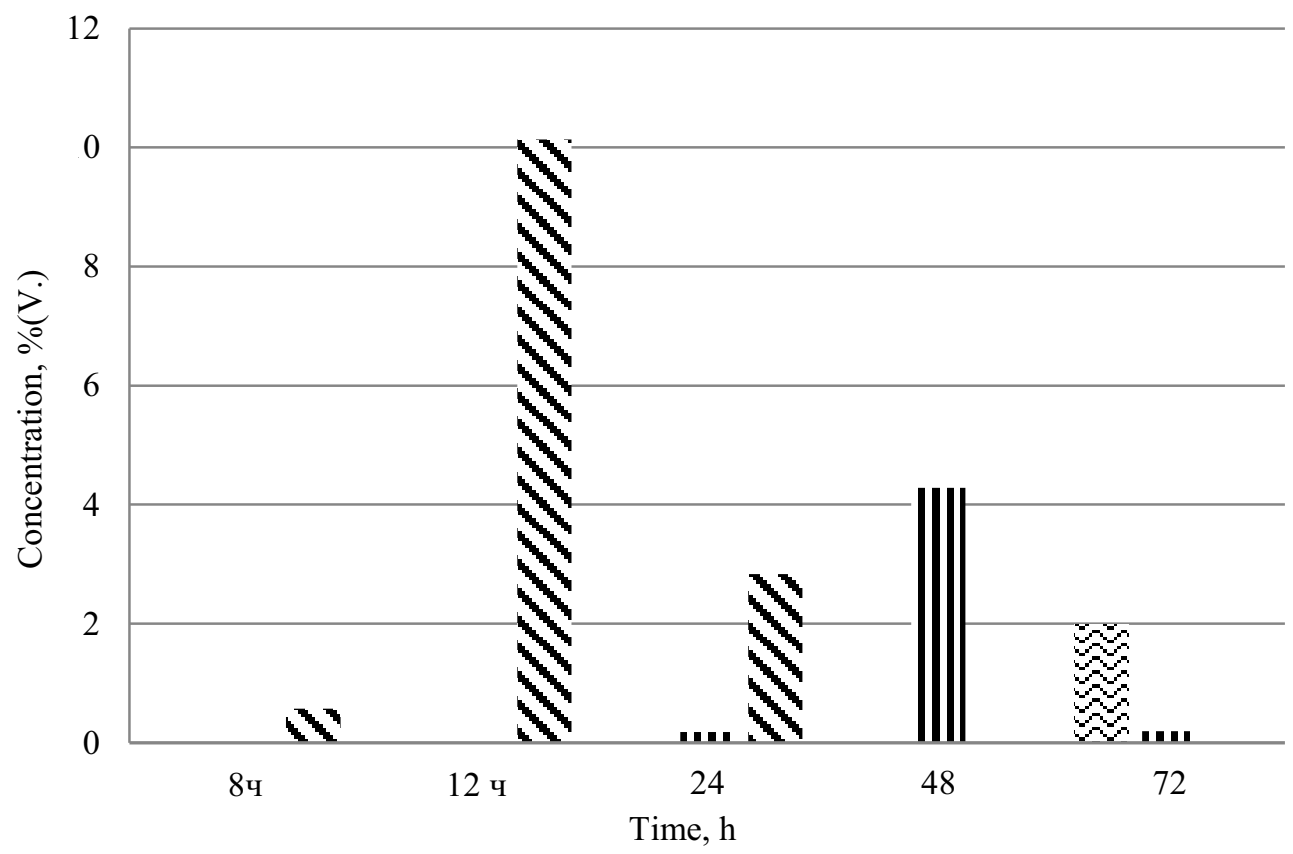

Figure 7. MEK content in the reaction mixture during the biotransformation by bacteria of the genus

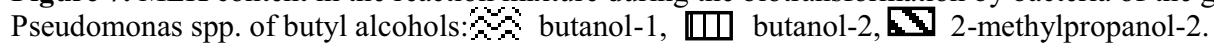

As it can be seen from the diagram (figure 7), MEK is observed in all cases, but the time of its formation is different. As expected, the isomer structure affects the rate of alcohol biotransformation. Therefore, MEK firstly forms in the reaction mixture in the case of using 2-methylpropanol-2 after 8 hours, and in the case of using n-butanol only after 72 hours. It should be assumed that the MEK formation occurs with the participation of the enzyme dehydrogenase complex [25], namely, alcohol dehydrogenase, which is responsible for catalyzing oxidation of alcohols and acetals to aldehydes and ketones in the presence of NAD (nicotinamide adenine dinucleotide). The highest MEK yield was observed when using 2-methylpropanol-2 after 12 hours of biosynthesis and accounted for $10 \%$.

\section{Conclusions}

MEK was obtained on the basis of microbiological synthesis of butyl alcohols with using bacteria of the genus Pseudomonas spp. The optimal conditions for the synthesis are 1\% (vol.) 2-methylpropanol-2, hydrocarbon-oxidizing bacteria of the genus Pseudomonas spp. with $108 \mathrm{CFU}$, temperature $30^{\circ} \mathrm{C}$, time 12 hours, and stirring speed $80 \mathrm{rev} / \mathrm{min}$. It should be considered that this method is an alternative method of obtaining MEK from the environmental and economic point of view.

\section{References}

1. T.A. Egorova, S.M. Klunova, E.A. Zhilukhina, Basics of Biotechnology, 208 (2008)

2. B.G. Sampat, Chemical Weekly July 5, 198-201 (2011)

3. K. Foxall, Health Protection Agency Version 1, 4 (2010)

4. D. Arora, M. Sharma, Chemical Weekly April 27, 189-194 (2010) 
5. S.A. Akimov, D.I. Perazich, A.N. Sokolov, A.I. Tsyvina, Patent USSR №583117 Method of MEK production (in Russian) (1977)

6. T.S. Zak, Patent US №4075128 Preparation of methyl ethyl ketone (1978)

7. S.I. Kryukov, A.V. Irodov, V.A. Smirnov, Patent USSR №825491 Process of MEK preparation (1981)

8. L.J. Velenyi, A.S. Krupa, Patent US №4329506 Isomerization of aldehydes to ketones (1982)

9. A.P. Khvorov, B.N. Gushchin, A.N. Petrov, D.M. Bayramgulov, S.M. Lakiza, V.I. Kotov, A.B. Guschevskiy, P.F. Tyugaev, Patent USSR №960160 Process of MEK preparation (1982)

10. B.L. Kozik, S.V. Pestrikov, Patent №165678 Process of MEK preparation (1984)

11. D.V. Mushenko, A.V. Grishchenko, G.M. Strashnova, V.S. Sobolevskiy, G.P. Cherkasov, A. P. Khvorov, V.I. Kotov, P. F. Tyugaev, V. N. Pavlychev, Patent USSR №2552716 Process of MEK preparation (1984)

12. A.B. Guschevskiy, M.L. Kolesov, et al. Modern problems of chemistry and chemical industry 8, 1-46 (1987)

13. M.L. Cook, J.D. Fellmann, D.R. Hamm, S. Mahajan, M.T. Muraoka, T. RostrupNielsen, A. R. Smith, J.H. Grate, R.J. Saxton, K.A. Klingman, Patent CA №2077549 Process for the production of methyl ethyl ketone (1991)

14. V.F. Odyakov, K.I. Matveev, T.A. Gorodetskaya, Z.P. Pai, L.N. Karandila, L.A. Stepanova, A.G. Nelin, D.B. Mushenko, F.A. Chernyshkova, G.N. Gvozdovskiy, Patent USSR №822417 Catalyst for the oxidation of ethylene to acetaldehyde or butylene to methyl ethyl ketone (1994)

15. K.I. Matveev, V.F. Odyakov, E.G. Zhizhina, Yu.A. Motornyi, S.A. Langue Patent №1669109 Catalyst for the oxidation of n-butelene to methyl ethyl ketone and process of its preparation (1995)

16. L. Berg, Patent US №5453166 Separation of ethanol from 2-butanone by extractive distillation (1995)

17. L. Berg Patent US №5876569 Separation of methyl ethyl ketone-from ethanol by extractive distillation (1999)

18. C.D. Murphy, Patent US №6121497 Process of recovering methyl ethyl ketone from an aqueous mixture of methyl ethyl ketone and ethanol (2000)

19. G. Marchionni, U.D. Patto, M. Avataneo, Patent US №7132051 B2 Liquid-liquid extraction of polar organic substances from their aqueous solutions with fluorinated extracting liquids(2003)

20. S.M. Aldoshin, P.E. Matkovsky, L.N. Russiyan, V.N. Troitsky, V.N. Parmon, Z.P. Pai, Patent №WO 2007055608 A2 Catalyst and process of methyl ethyl ketone preparation (2007)

21. GOST R 52714-2007 Motor gasolines. Determination of individual and group hydrocarbon composition by method of capillary gas chromatography //URL: http://allgosts.info/standarts/gost-r-52714-2007

22. T.H. Lee, J. Kim, M.J. Kim, H.W. Ryu, K.S. Cho, Chemosphere 63, 315-322 (2006)

23. A.P. Astashkina, A.A. Bakibayev, E.V. Plotnikov, Yu.V. Kolbysheva, A.B Mukashev, Procedia chemistry 10, 504-507 (2015)

24. V.V. Smirnov, E.A. Kiprianova, Bacteria of the genus Pseudomonas, 264 (1990)

25. A.M. Bezborodov, Biochemical basis of microbiological synthesis, 304 (1984)

26. K.A. Leonov, A.P. Astashkina, A.A. Bakibayev, Procedia chemistry 10, 504-507 (2014)

27. G.K. Skryabin, L.A. Golovleva, Using micro-organisms in organic synthesis, 332 (1976) 